\title{
Article
}

\section{Feasibility of Using Non-Destructive Ultrasound Measurement Technique to Evaluate Binder Content of Asphalt Mixtures}

\author{
Kazem Jadidi $^{1}$ (D), Mehdi Khalili ${ }^{2}$ and Moses Karakouzian ${ }^{1, *(D)}$ \\ 1 Howard R. Hughes College of Engineering, University of Nevada, Las Vegas, NV 89154, USA; \\ Kazem.jadidi@unlv.edu \\ 2 Geosyntec Consultants, Johnson City, TN 37601, USA; MKhalili@geosyntec.com, \\ * Correspondence: Mkar@unlv.nevada.edu
}

Citation: Jadidi, K.; Khalili, M.; Karakouzian, M. Feasibility of Using Non-Destructive Ultrasound Measurement Technique to Evaluate Binder Content of Asphalt Mixtures. CivilEng 2021, 2, 396-405. https:// doi.org/10.3390/civileng2020022

Academic Editors: Luis Picado-Santos and Mohammad Saberian Boroujeni

Received: 4 February 2021

Accepted: 18 May 2021

Published: 21 May 2021

Publisher's Note: MDPI stays neutra with regard to jurisdictional claims in published maps and institutional affiliations.

Copyright: (c) 2021 by the authors. Licensee MDPI, Basel, Switzerland. This article is an open access article distributed under the terms and conditions of the Creative Commons Attribution (CC BY) license (https:// creativecommons.org/licenses/by/ $4.0 /)$.

\begin{abstract}
The non-destructive ultrasound technique is an easy and inexpensive technique widely used in industry to evaluate the properties of engineering materials. Despite its popularity in industrial applications, such as evaluating steel materials, the ultrasound technique has not been thoroughly investigated for the purpose of characterizing asphalt materials in general, nor specifically determining the asphalt binder content of asphalt mixtures. The purpose of this study was to explore the feasibility of utilizing measurements based on the non-destructive ultrasound technique to detect changes in the asphalt binder content in asphaltic mixture specimens. Two performance-grade binders, PG64-28 and PG76-22, and two rubber-modified binders were selected. The rubber-modified binders were produced by adding crumb rubber to the two performance-grade binders, PG64-28 and PG76-22, and were designated as PG64-28R and PG76-22R. The amount of crumb rubber added to these rubber-modified binders was $15 \%$ by weight of the PG64-28 and PG76-22 binders. The aggregate gradations for all of the asphalt mixtures were the same. The asphalt mixture specimens were used to obtain measurements for: (1) the ultrasound wave speed through the specimens; and (2) and the integrated response (IR) of the specimens. The results indicated that, generally, the ultrasound wave speed decreases with an increase in binder content. This is expected due to the binder's attenuation and slowing effect on the wave speed. The results also indicated that, generally, the integrated response (IR) decreases with an increase in binder content. This can be explained by the fact that the increased binder content in asphalt mixture specimens increases their tendency to absorb more energy.
\end{abstract}

Keywords: asphalt mixture; rubberized asphalt binder; NDT; ultrasound; wave speed; integrated response

\section{Introduction}

The feasibility of using the ultrasound technique to characterize asphalt binders and mixtures has been investigated by several researchers. Krishnan [1] and Khalili et al. [2] investigated the asphalt binders using the non-contact ultrasound technique. They suggested that the ultrasound speed decreased with an increase in the temperature of the binder. Tigdemir et al. [3] investigated the fatigue properties of asphalt mixtures using an ultrasound technique. They suggested that fatigue properties could be predicted by ultrasound techniques. Sztukiewicz [4] found that the ultrasound wave speed increased with the increase in bulk-specific gravity. Dunning et al. [5] developed correlations between the (1) ultrasound speed and (2) integrated response (IR) and the bulk-specific gravities and dynamic moduli of asphalt mixtures. Other researchers [6,7] also reported correlations of ultrasound measurements to shear and dynamic moduli. Mounier et al. [8] measured the linear properties of asphalt mixtures with ultrasound and concluded that determining the complex modulus of an asphalt mixture was possible by measuring the ultrasound wave speed and the IR with an error below $20 \%$. They also stressed the importance of selecting 
an appropriate wave frequency to obtain good results. Zavrtanik et al. [9] reported that the change in the coefficient of the shear wave reflection increased with the decrease in material temperature for both grade binders and polymer-modified binders. Franesqui et al. [10] reported that ultrasonic measurements have the potential in determining crack depth in asphalt pavement. Norambuena-Contreras et al. [7] indicated that ultrasound measurement resulted in higher dynamic moduli for asphalt mixtures when compared with those obtained by standard modulus tests.

\section{Motivation and Purpose}

The literature review in the introduction of this paper indicates that although ultrasound technique has been investigated for the purpose of characterizing asphalt materials in general, the literature is lacking in research to directly and specifically quantify the asphalt binder content of asphalt mixtures. The purpose of this study was to investigate the feasibility of using a non-destructive ultrasound measurement technique to evaluate the binder content of asphalt mixtures containing traditional (virgin) and rubberized asphalt binders.

\section{Ultrasound Technique Background and Equipment}

\subsection{Ultrasound Technique Background}

Ultrasound testing devices generate three types of waves which are applicable to material testing. These waves include longitudinal, shear and surface waves. The velocity of wave in materials, in the direction of the wave propagation, is calculated using Equation (1):

$$
V_{\varphi}=\frac{\omega}{k}=f \lambda
$$

where $\omega$ is the angular velocity, $f$ is frequency, $\lambda$ is wavelength and $k$ is wave number [11].

It is possible to directly measure the wavelength with an ultrasound device. Knowing the distance between the two transducers and the thickness of the specimen, the pulse velocity in the specimen can be determined using Equation (2):

$$
V_{m}=\frac{d}{\frac{L-d}{V_{a}}-t}
$$

where $V_{m}$ is the pulse velocity of the material (specimen), $L$ is the distance between two transducers, $d$ is the specimen thickness, $V_{a}$ is the ambient medium pulse velocity and $t$ is the pulse time [12]. Integrated response (IR) is another parameter which is being measured and analyzed with ultrasound surveying. Equations (3) and (4) are used to measure this parameter:

$$
\begin{aligned}
& I R_{1}=20 \log R_{\frac{I}{I}} \\
& I R_{2}=20 \log T_{\frac{I I}{I}}
\end{aligned}
$$

where $I R_{I}$ and $I R_{I I}$ are the integrated response for the reflection from the top and bottom of the specimen, respectively, and $\mathrm{R}_{\mathrm{I} / \mathrm{II}}$ is the reflection coefficient and $\mathrm{R}_{\mathrm{II} / \mathrm{I}}$ is the transmission coefficients at the interface of the specimen. Equations (5) and (6) are used to calculate the reflection coefficient and transmission coefficient:

$$
\begin{gathered}
R=\left(\frac{Z_{I I}-Z_{I}}{Z_{I I}+Z_{I}}\right)^{2} \\
T=1-R=1-\left(\frac{Z_{I I}-Z_{1}}{Z_{I I}+Z_{I}}\right)^{2} .
\end{gathered}
$$

where $Z I$ and ZII are the acoustic impedances for materials 1 and 2 [13]. 


\subsection{Ultrasound Equipment and Measurement Method}

Selecting a suitable transducer with appropriate properties was a major challenge. Considering the fact that the asphalt samples were made with various binder types and contents, it was necessary to select a set of transducers with the capability of covering all mixture types. In this research, the contact pulser-receiver method was used to measure the flight time inside the asphalt mix cylinders. Figure 1 shows an ultrasound surveying set up on a test specimen. In order to obtain a reliable wave shape, it is necessary to have a perfect contact between the transducer and the asphalt sample. To achieve this goal, a gel was used to smoothen and flatten the surfaces of the samples.
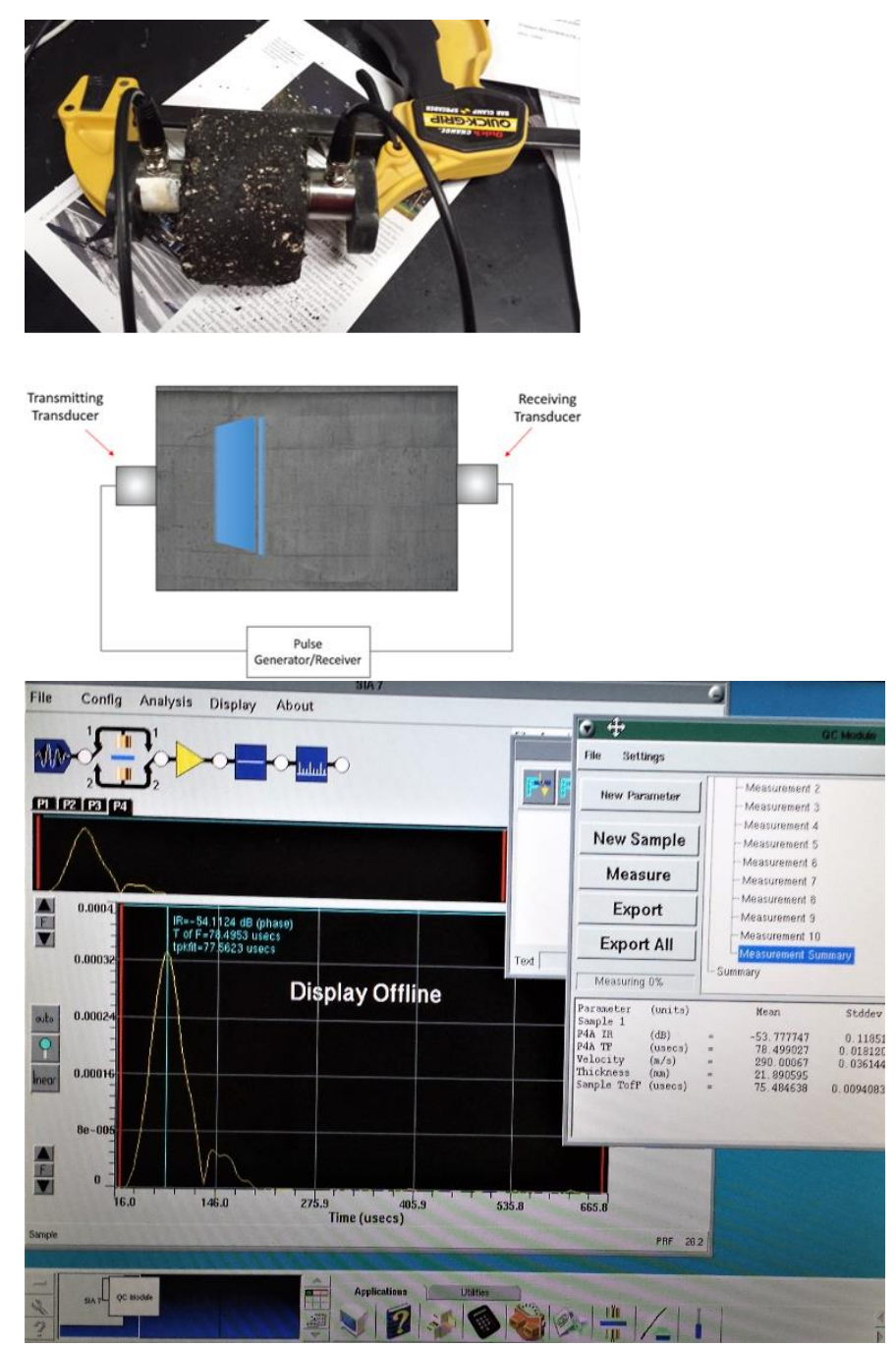

Figure 1. Ultrasound wave propagation on an asphalt sample.

Originally, the goal of this study was to measure the wave properties in the middle and the edges of the samples; however, due to many irregularities on the surfaces of the samples, the measurement was performed only in the middle of each specimen. Moreover, the best frequency and configuration for this study was determined after performing several trial experiments on specimens with different types of transducers.

First, a transducer with a $900 \mathrm{kHz}$ frequency was used; however, it did not produce an appropriate wave in response. Nonetheless, a transducer type known as Ultra ZRD 100-2 NCA 1000, which propagates longitudinal waves with a $125 \mathrm{kHz}$ frequency, created a reliable wave, and was selected to be used in this experiment. The required settings for the pulser-receiver of the mentioned transducer are presented in Table 1. After selecting 
the test method and transducer, contact wave propagation was performed on each sample ten times and the average was recorded. The reason for performing so many times was to illuminate any error and unreliable recordings which were possible due to the mixture specimens' pretty rough surface.

Table 1. Required settings for the pulser-receiver of the transducer.

\begin{tabular}{ccc}
\hline Item & Unit & Setting \\
\hline Type & - & Ultra ZRD 100-2 NCA 1000 \\
Frequency & $\mathrm{kHz}$ & 225 \\
Bandwidth & $\mathrm{kHz}$ & 56 \\
Duration & $\mu \mathrm{sec}$ & 150 \\
Amplitude & $\%$ & 75 \\
Chirp Step-A & $\%$ & 45 \\
Chirp Step-B & $\%$ & 45 \\
\hline
\end{tabular}

The literature analysis indicates that this testing tool has not been studied very well in terms of investigating the properties of asphalt mixtures. Despite being commonly used in the material testing industry, very few academic studies are available in terms of using it in analyzing bituminous materials. In this research, asphalt mixture cylinders were produced by different types of binder and subjected to ultrasonic surveying. The results were analyzed to determine any correlation between wave speed and integrated response as well as asphalt mixture.

\section{Materials and Methods}

In this study, the wave speed and integrated response were measured and analyzed on the asphalt mixture specimen. Asphalt binder was provided from local manufacturers in Nevada. Two different performance grades binders, PG64-16 and PG58-28, and one viscosity grade binder, AC20, were provided for this investigation [14]. In order to consider the properties of rubber-modified mixtures, a set of modified specimens was also manufactured. The rubber content in the rubber-modified binder was $15 \%$ in accordance with the results of an investigation performed in Nevada on rubberized asphalt $[15,16]$. Moreover, the type $2 \mathrm{C}$ aggregate, which is presented in Table 2, was provided from the local suppliers in Nevada to produce the required mixtures.

Table 2. Properties of aggregates from southern Nevada.

\begin{tabular}{|c|c|c|c|c|c|}
\hline \multicolumn{2}{|c|}{ Sieve } & \multicolumn{2}{|c|}{ Type 2C } & \multirow[b]{2}{*}{ Parameter } & \multirow[b]{2}{*}{ Value } \\
\hline Size & $\mathrm{mm}$ & Range & Midpoint & & \\
\hline 1 in & 25 & 100 & 100 & Coarse $\mathrm{G}_{\mathrm{s}}$ & 2.63 \\
\hline $3 / 4$ in & 19 & $88-95$ & 91.5 & Fine $\mathrm{G}_{\mathrm{s}}$ & 2.51 \\
\hline $1 / 2$ in & 12.5 & $70-85$ & 77.5 & Sand Equivalent & 81 \\
\hline $3 / 8$ in & 9.5 & $60-78$ & 69 & Los Angeles Abrasion & 15.7 \\
\hline No. 4 & 4.75 & $43-60$ & 51.5 & & \\
\hline No.10 & 2 & $30-44$ & 37 & & \\
\hline No. 40 & 0.425 & $12-22$ & 17 & & \\
\hline No. 200 & 0.075 & $3-8$ & 5.5 & & \\
\hline
\end{tabular}

The ultrasound testing apparatus was used in this experiment. The following steps were followed to obtain the required results.

- The best type of transducer for performing the test should be selected; in this study, it is presented in Table 3. 
Table 3. Optimum binder content.

\begin{tabular}{cccc}
\hline $\begin{array}{c}\text { Binder } \\
\text { (Type) }\end{array}$ & $\begin{array}{c}\text { Rubber } \\
\text { (Percent/Type/Size) }\end{array}$ & $\begin{array}{c}\text { Optimum } \\
\text { Binder Content } \\
\mathbf{( \% )}\end{array}$ & $\begin{array}{c}\text { Number of } \\
\text { Specimens }\end{array}$ \\
\hline PG 76-22 & None & 5.8 & 5 \\
PG 76-22 R & 15\% Terminal Blend & 6.0 & 5 \\
PG 64-28 & None & 5.0 & 5 \\
PG 64-28 R & 15\% Terminal Blend & 5.0 & 5 \\
\hline
\end{tabular}

- The apparatus selected — such as the transducer, pulser, and receiver-was checked with different mixes and samples to see whether any changes in the mixes affected the results and determine whether adjustments needed to be made to ensure that the testing equipment was working properly.

- The best scanning method should be selected for correlating ultrasonic measurements with the properties of hot mix asphalt (HMA); for this study, the method used was the contact method.

\section{Volumetric Properties of Asphalt Mixtures}

Asphalt mixture specimens were prepared in accordance with Test Method Nev. T303. The specimens were cylindrical with $100 \mathrm{~mm}$ diameters and $65 \mathrm{~mm}$ heights. For each of the four binder types, triplicate specimens were prepared at $4.0 \%, 4.5 \%, 5 \%, 5.5 \%$ and $6.0 \%$ binder content. In this research, the Hveem mix design method was used in accordance with Test Method Nev. T760C to produce the mixture specimens [17]. In order to compact the samples and run the stability test, Test Method Nev. T303 [18] was used and cylindrical specimens with approximately $100 \mathrm{~mm}$ diameter and $65 \mathrm{~mm}$ height were manufactured. Then, the volumetric properties of the asphalt mix samples were obtained, and various density measurements were conducted based on Test Method Nev. T333 and AASHTO T $209[19,20]$. Finally, the air void content was calculated in accordance with to Test Method Nev. T338B and AASHTO T 269 [21,22]. The volumetric properties of rubber-modified binder samples manufactured with various types of binders are illustrated in Figure 2.
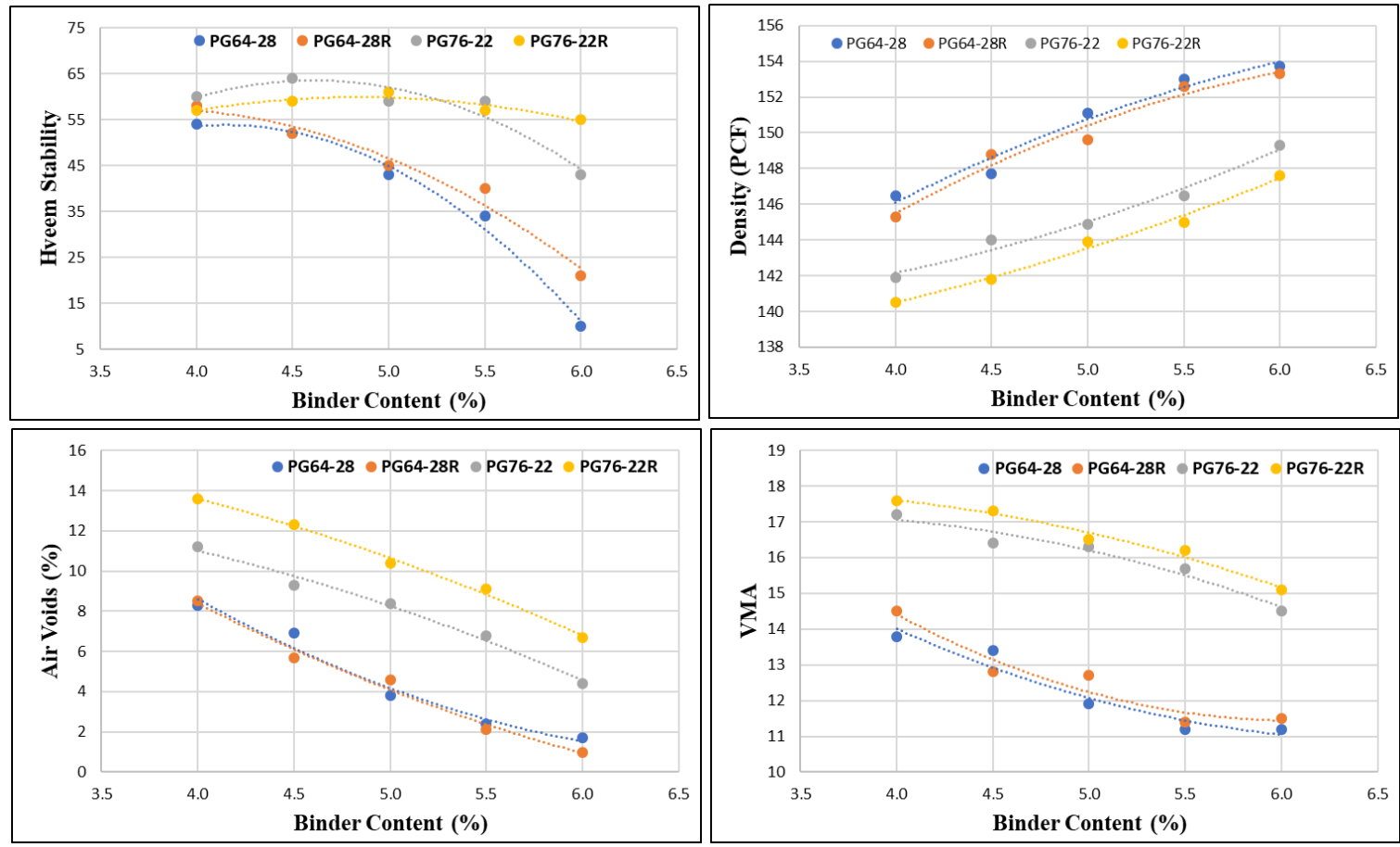

Figure 2. Mix design properties of four binder specimens. 
Meanwhile, the results of the analysis of the volumetric and stability behavior of the asphalt mix samples are presented in Table 3. As can be observed in Table 3, compared to traditional asphalt mixtures, e.g., mixtures made with non-modified binder, modifying asphalt with rubber, led to a relatively higher optimal binder content. Rubber improved the capability of asphalt to be mixed with a higher binder content, probably because rubber has a higher absorption rate compared to regular binder and absorbs part of the binder. This is due to the surface area of the rubber particles, especially for ambient ground rubber. Another probable reason relates to the surface of the aggregates and the way that rubber-modified bitumen fills the voids between aggregates.

\section{Results}

In this investigation, for every binder content and asphalt type, three samples were produced and tested. Several representatives were highly damaged or had uneven surfaces, and so it was impossible to obtain a reliable wave response; as a result, these samples were eliminated. Figures 3 and 4 exhibit the results of the measurements for all the samples. In these graphs, the average of the wave speed, which was calculated based on the wave flight time in mixture samples and the thickness of each specimen, is presented against the binder content.

\subsection{Ultrasound Wave Speed}

Taking a closer look at the graph presented in Figure 3 reveals that, in general, the wave speed decreased with an increase in binder content for asphalt specimens made with the PG 64-28 binder type. However, as it is indicated in Figure 4, for PG76-22 TR, the data at $5 \%$ binder seem to fall and do not follow a normal trend. The authors attribute this anomaly to several possible causes: a damaged (cracked) specimen, the uneven distribution of rubber in the specimen, and the partial contact of the transducer with the specimen's rough surface. In addition, Hveem stability for PG76-22 and PG76-22R in Figure 2 in the manuscript) is almost constant as the binder content changes. This may be another possible explanation for this anomaly. This difference in wave-speed trends possibly demonstrates the influence of the binder type and the aggregate source on the ultrasound properties of asphalt mixture, however, the researchers are not currently able to explain this anomaly.

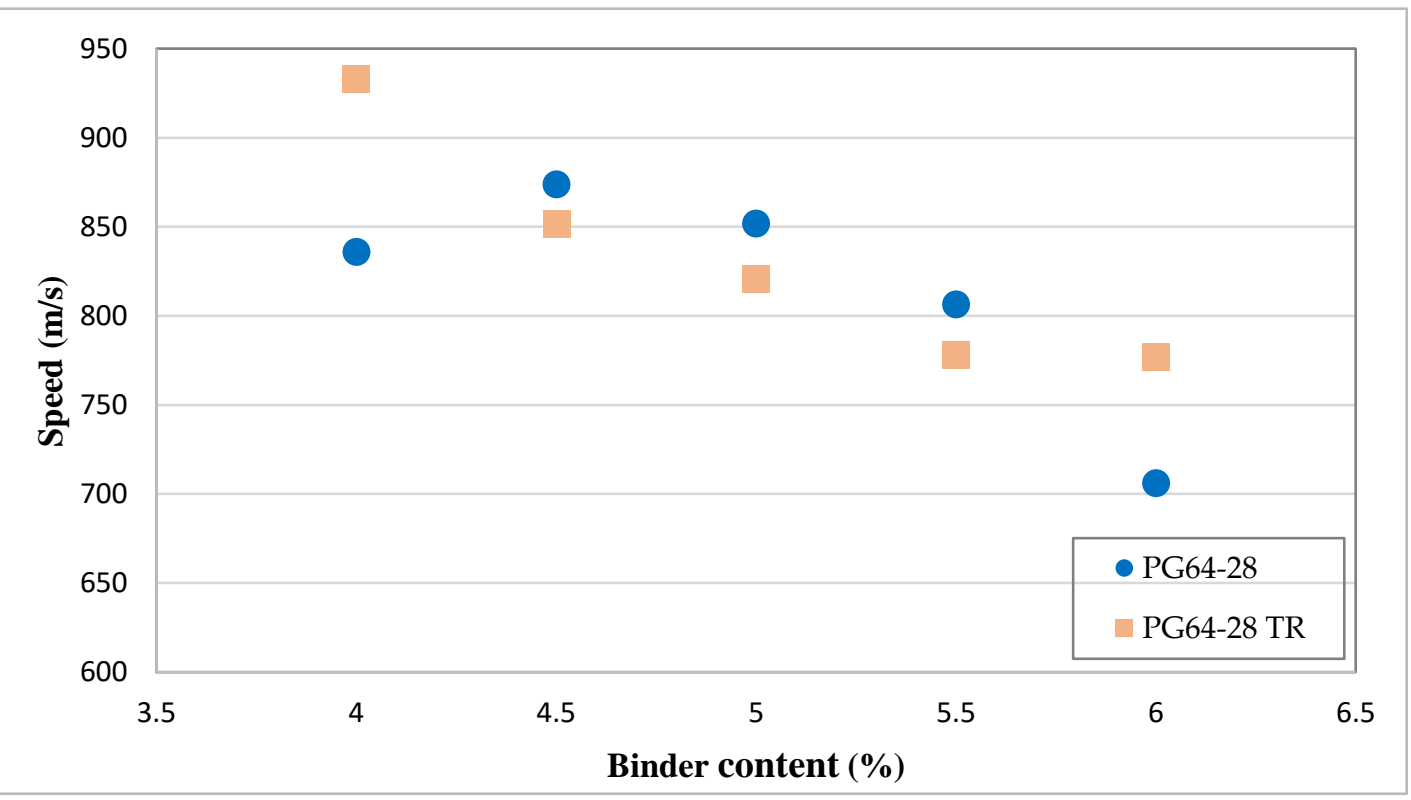

Figure 3. Wave speed trend with asphalt binder content for PG64-28 specimens. 


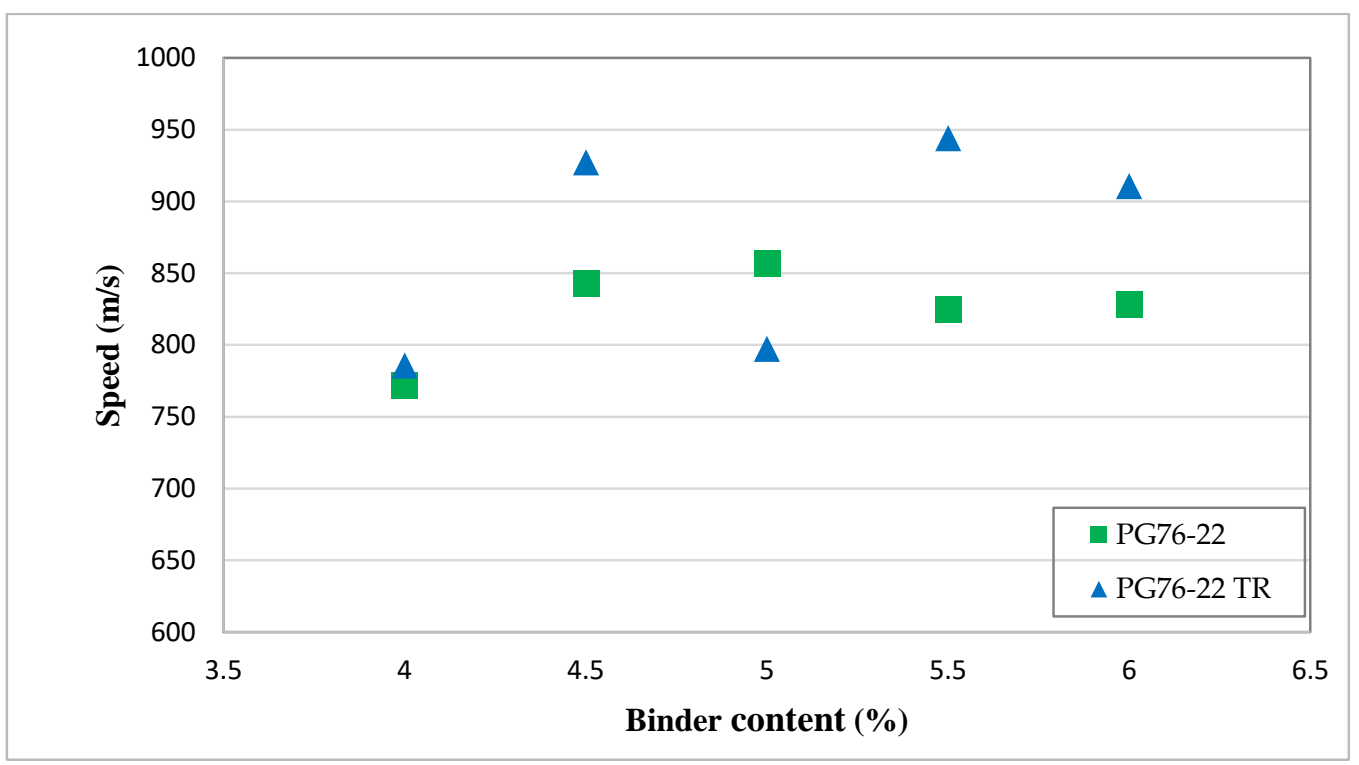

Figure 4. Wave speed trend with asphalt binder content for PG74-22 specimens.

\subsection{Ultrasound Integrated Response}

The results of the integrated response measurements generally indicate decreased integrated response values with increased binder content for all four binder types (Figures 5 and 6). This can be explained by the fact that increased binder content in asphalt mixture specimens increases the tendency of specimens to absorb more energy. Accordingly, a decrease in integrated response is observed with increased binder content. Additionally, the decreased integrated response for specimens with binders containing crumb rubber is less than for those without crumb rubber. This difference in decreased integrated response was due to the increased elastic recovery of crumb rubber in the binder. Mashaan et al. (2011) showed that the elastic recovery of a binder increases as the crumb rubber content increases [23]. The increased elastic recovery in the binder allows an increased amount of ultrasonic energy to be transmitted (transmissivity) or reflected (reflectivity) from a test material. Accordingly, less energy is lost in specimens with crumb rubber binders than in those without crumb rubber.

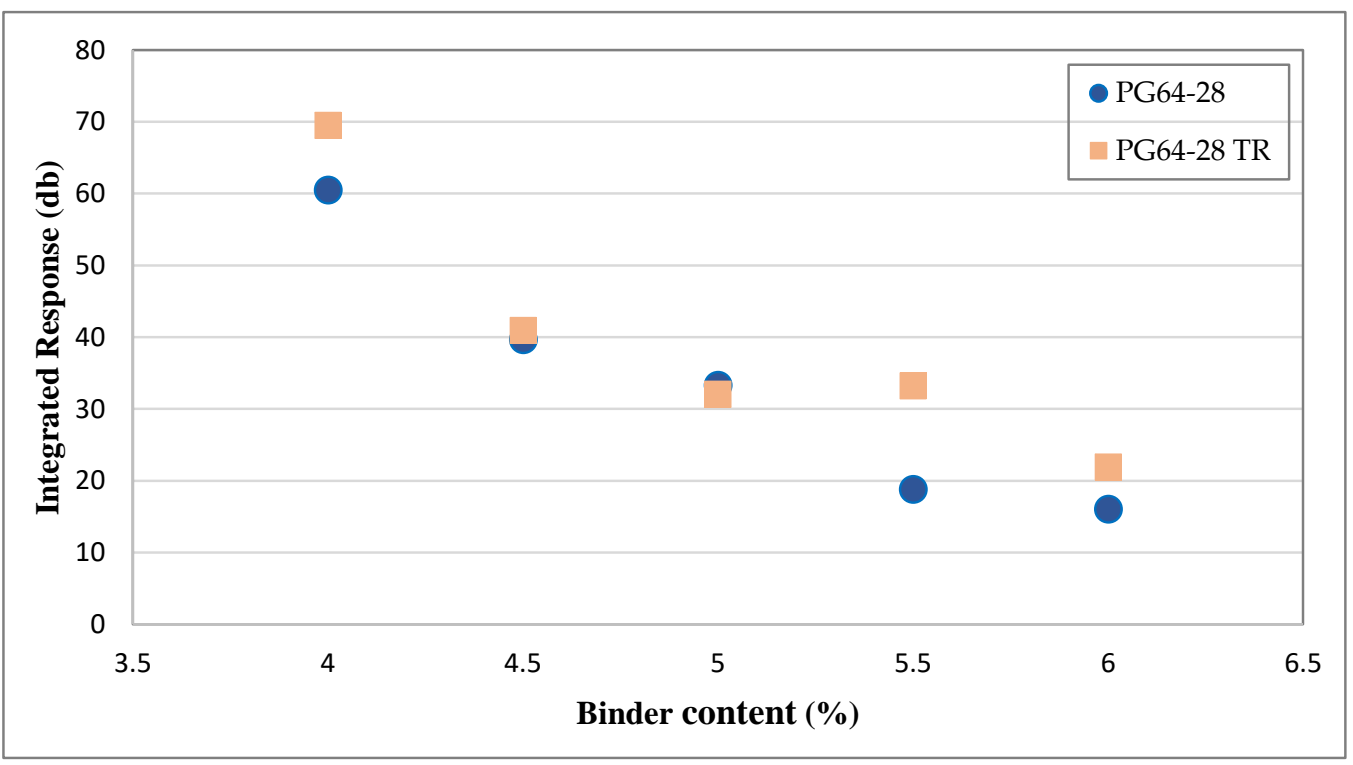

Figure 5. Wave integrated response trend with binder content for PG 64-28 mix. 


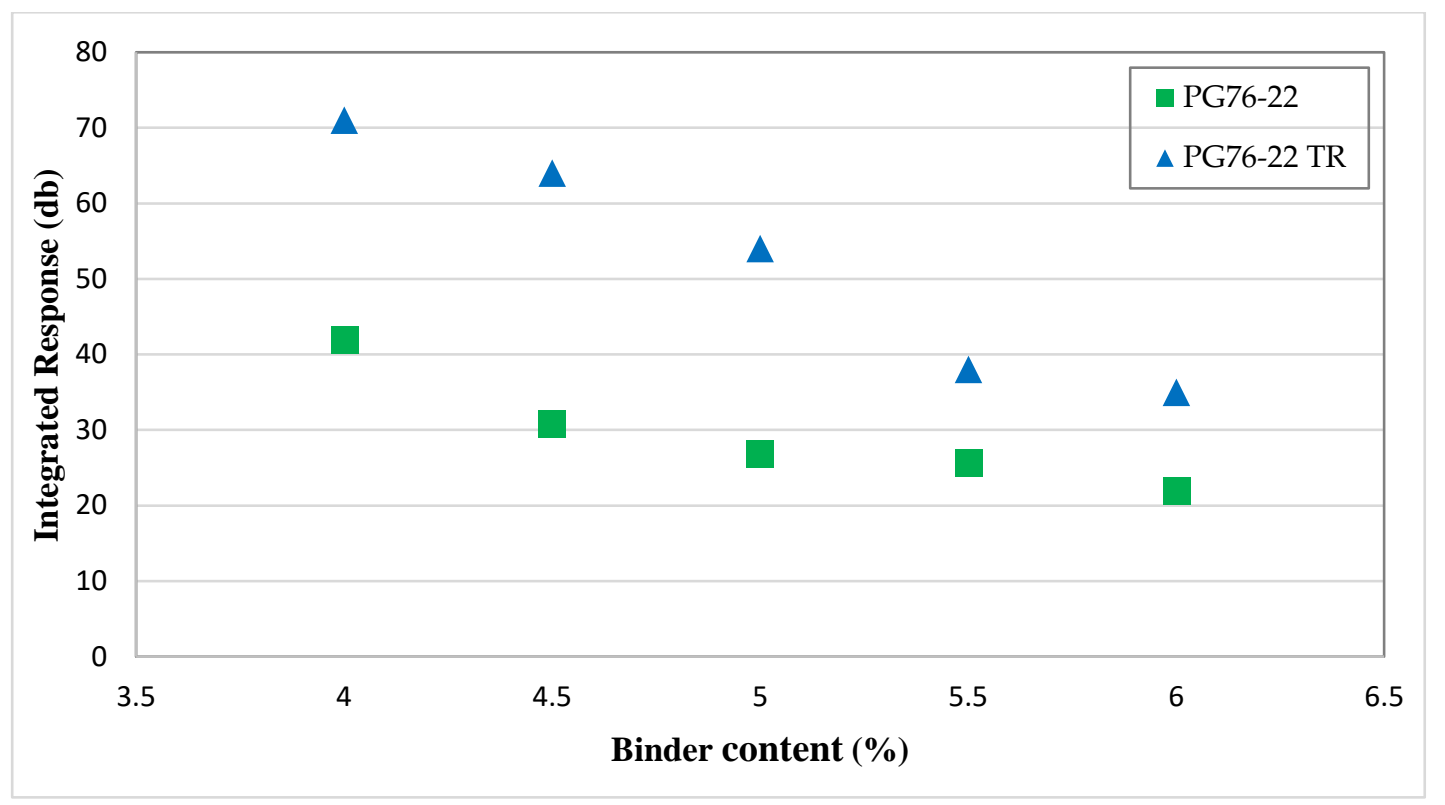

Figure 6. Wave integrated response trend with binder content for PG 76-22 mix.

Overall, the results indicated that, generally, the ultrasound wave speed decreases with an increase in binder content. This was expected due to the binder's attenuation and slowing effect on the wave speed. However, no significant trend was observed for mixtures made with the PG76-22 and PG76-22R binder types. The researchers are not able to explain with confidence this anomaly at this time. However, the Hveem stability for PG76-22 and PG76-22R in Figure 2 is almost constant as the binder content changes. This may be a possible explanation.

The results also indicated that, generally, the integrated response (IR) decreases with an increase in binder content. This can be explained by the fact that the increased binder content in asphalt mixture specimens increases their tendency to absorb more energy.

\section{Conclusions}

In this study, the Hveem mix design was used to produce asphalt mixture specimens with four different binder types: two performance grade binders, PG64-28 and PG76-22, and two binders with crumb rubber, designated as PG64-28R and PG76-22R. For each of the four binder types, triplicate asphalt mixture specimens were prepared at $4.0 \%, 4.5 \%$, $5 \%, 5.5 \%$ and $6.0 \%$ binder content. Ultrasound measurements (integrated response and wave speed) were obtained and analyzed. The following conclusions were made:

- Integrated response measurements generally indicate a decrease in integrated response values with the increasing binder content for all four binder types. This can be explained by the fact that increased binder content in asphalt mixture specimens increases the tendency of the specimens to absorb more energy.

- The decreased integrated response for specimens with binders containing crumb rubber is less than those without crumb rubber. This difference is due to the increased elastic recovery of crumb rubber in the binder.

- The wave speed decreased with the addition of binder content for specimens produced with PG64-28 and PG64-28R. This was expected due to the binder's attenuation and slowing effect on wave speed.

- No significant trend of wave speed was observed for mixtures made with PG76-22 and PG76-22R binder types. The researchers are not able to explain with confidence this anomaly at this time. However, the Hveem stability for PG76-22 and PG76-22R in Figure 2 is almost constant as the binder content changes. This may be a possible explanation. 
- Overall, this study shows that the non-destructive ultrasound measurement technique has potential to evaluate the binder content of asphalt mixtures. However, further research is recommended

Author Contributions: K.J. performing ultrasound and volumetric tests, main author; M.K. (Mehdi Khalili), performing volumetric tests, M.K. (Moses Karakouzian), supervisor, main technical editor. All authors have read and agreed to the published version of the manuscript.

Funding: This paper did not receive any funding.

Data Availability Statement: Data sharing is not applicable to this article.

Acknowledgments: This paper was based on a founded project with the Nevada Department of Transportation (NDOT) at the University of Nevada Las Vegas (UNLV).

Conflicts of Interest: This article does not have any conflict of interest.

\section{References}

1. Krishnan, A. Material Characterization of Asphalt Binder Using Ultrasound Testing. Master's Thesis, University of Nevada, Las Vegas, NV, USA, 2007.

2. Khalili, M.; Karakouzian, M. Feasibility of ultrasonic measurements for characterizing rheological properties of asphalt binders. Constr. Build. Mater. 2015, 75, 220-226. [CrossRef]

3. Tigdemir, M.; Kalyoncuoglu, S.F.; Kalyoncuoglu, U.Y. Application of Ultrasound Method in Asphalt Concrete Testing for Fatigue Life Estimation. NDT E Int. 2004, 37, 597-602. [CrossRef]

4. Sztukiewicz, R.J. Application of Ultrasonic Method in Asphalt Concrete Testing. Ultrasonics 1991, 29, 5-12. [CrossRef]

5. Dunning, M.; Karakouzian, M.; Dunning, R. Feasibility of the Use of Non-Contact Ultrasound for Application in Asphalt Concrete Materials. J. Assoc. Asph. Paving Technol. 2007, 76, 851-886.

6. Van Velsor, J.K.; Premkumar, L.; Chehab, G.; Rose, J.L. Measuring the Complex Modulus of Asphalt Concrete using Ultrasonic Testing. J. Eng. Sci. Technol. Rev. 2011, 4, 160-168. [CrossRef]

7. Contreras, J.N.; Fresno, D.C.; Zamanillo, A.V.; Celaya, M.; Vozmedano, I.L. Dynamic Modulus of Asphalt Mixture by Ultrasonic Direct Test. NDT E Int. 2010, 43, 629-634. [CrossRef]

8. Mounier, D.; Benedetto, H.D.; Suzeat, C. Determination of Bituminous Mixtures Linear Properties using Ultrasonic Wave Propagation. Constr. Build. Mater. 2012, 36, 638-647. [CrossRef]

9. Zavrtanik, N.; Turk, G.; Tušar, M.; Trtnik, G. Monitoring of Bitumen Hardening with Non-destructive Ultrasonic Shear Wave Reflection Technique. Int. J. Pavement Eng. 2016, 18, 560-566. [CrossRef]

10. Franesqui, M.A.; Yepes, J.; García-González, C. Ultrasound data for laboratory calibration of an analytical model to calculate crack depth on asphalt pavements. Data Brief 2017, 13, 723-730. [CrossRef] [PubMed]

11. Ellingson, S.D. Phase and Group Velocity. Virginia Tech Libraries Open Education Institute, Retrieved. September 2020. Available online: https://phys.libretexts.org/Bookshelves/Electricity_and_Magnetism/Book\%3A_Electromagnetics_II_(Ellingson)/0 6\%3A_Waveguides /6.01\%3A_Phase_and_Group_Velocity (accessed on 20 May 2021).

12. Bhardwaj, M.C.; Neeson, I.; Stead, G. Introduction to Contact-Free Ultrasonic Characterization and Analysis of Consolidated Materials. NDT. Net 5.6 (2000). Available online: https:/ / www.ndt.net/article/v05n06/bhardwaj/bhardwaj.htm (accessed on 20 May 2021).

13. Bhardwaj, M.C. Non-Contact Ultrasound: The Final Frontier in Non-Destructive Analysis; Second Wave Systems: Boalsburg, PA, USA, 2002.

14. Jadidi, K.; Khalili, M.; Karakouzian, M.; Amirkhanian, S. Toughness, Tenacity and Maximum Initial Strength of Rubber Modified Asphalt Binders. Eng. Technol. Appl. Sci. Res. 2019, 9, 3765. [CrossRef]

15. Khalili, M.; Jadidi, K.; Karakouzian, M.; Amirkhanian, S. Rheological properties of modified crumb rubber asphalt binder and selecting the best modified binder using AHP method. Case Stud. Constr. Mater. 2019, 11, e00276. [CrossRef]

16. Khalili, M.; Amirkhanian, S.N.; Karakouzian, M.; Xiao, F.; Jadidi, K. Evaluation of New Innovations in Rubber-Modified Asphalt Binders and Rubberized Asphalt Mixes for Nevada DOT (No. 513-13-803); Department of Transportation: Las Vegas, NV, USA, 2016.

17. Method of Test for Determining Optimum Bitumen Ratio of Bituminous Paving Mixtures; Nev. T760C; Nevada Department of Transportation: Las Vegas, NV, USA, November 2007.

18. Method of Test to Compact and Perform Stability Test on Compacted Bituminous Mixtures; Nev. T303; Department of Transportation: Las Vegas, NV, USA, October 2005.

19. Method of Test to Calculate Weight per Cubic Foot of Compacted Bituminous Mixtures; Nev. T333B; Department of Transportation: Las Vegas, NV, USA, October 2005.

20. American Association of State Highway and Transportation Officials. Standard Method of Test for Theoretical Maximum Specific Gravity (GMM) and Density of Hot Mix Asphalt (HMA); AASHTO T 209; January 2012. Available online: https://standards. globalspec.com/std/14316827/aashto-t-209 (accessed on 20 May 2021). 
21. Method of Test to Determine Voids in Minerals Aggregate of Compacted Bituminous Mixtures; Nev. T338B; Department of Transportation: Las Vegas, NV, USA, October 2005.

22. American Association of State Highway and Transportation Officials. Standard Method of Test for Percent Air Voids in Compacted Dense and Open Asphalt Mixtures; AASHTO T 269; January 2014. Available online: https:/ / standards.globalspec.com/std/130533 44/AASHTO\%20T\%20269 (accessed on 20 May 2021).

23. Mashaan, N.S.; Ali, A.H.; Karim, M.R.; Abdelaziz, M. Effect of crumb rubber concentration on the physical and rheological properties of rubberised bitumen binders. Int. J. Phys. Sci. 2011, 6, 684-690. 